\title{
Exploring and Developing the Workplace Health Culture Scale in Taiwan
}

\author{
Yao-Tsung Chang ${ }^{1}$, Feng-Jen Tsai ${ }^{2}$, Chien-Chih Kuo ${ }^{3}$, Ching-Ying Yeh ${ }^{1}$ and \\ Ruey-Yu Chen ${ }^{\text {** }}$ \\ 'School of Public Health, Taipei Medical University, Taipei, Taiwan, ${ }^{2}$ PhD Program in Global Health and Health Security, and \\ Master Program in Global Health and Development, College of Public Health, Taipei Medical University, Taipei, Taiwan, \\ ${ }^{3}$ Department of Psychology, National Cheng-Chi University, Taipei, Taiwan
}

OPEN ACCESS

Edited by:

Danijela Gasevic,

Monash University, Australia

Reviewed by:

Enid Chung Roemer,

Johns Hopkins University,

United States

Siti Munira Yasin,

Universiti Teknologi MARA, Malaysia

*Correspondence:

Ruey-Yu Chen

rueyyu@tmu.edu.tw

Specialty section:

This article was submitted to Occupational Health and Safety,

a section of the journal

Frontiers in Public Health

Received: 26 August 2019 Accepted: 10 December 2019 Published: 10 January 2020

Citation:

Chang Y-T, Tsai F-J, Kuo C-C Yeh C-Y and Chen R-Y (2020)

Exploring and Developing the Workplace Health Culture Scale in Taiwan. Front. Public Health 7:397. doi: 10.3389/fpubh.2019.00397
Background: The aim of this study was to develop and validate the workplace health culture scale.

Methods: This paper collected and re-organized current definitions about health culture from literature and created the domains and items to develop a new tool. Six enterprises and 2,431 participants were recruited from northern Taiwan for validity test.

Results: We found the workplace health culture scale had appropriate reliability and validity, including a good model fit for the 25 -item scale.

Conclusions: Workplace health culture might be an important domain to the work of WHP. More validity and reliability studies about WHCS in wider industries and the correlation between WHCS and other WHP indicators are needed.

Keywords: workplace health culture, scale, factor analysis, workplace health promotion, health behavior

\section{BACKGROUND}

Many chronic diseases like cardiovascular diseases and type 2 diabetes are associated with obesity. Most of these are caused by the increasing sedentary lifestyles, unhealthy diets, and many other facets of an unhealthy lifestyle $(1,2)$. Since most adults have over half of their waking time working in the workplaces, to promote people's healthy behaviors and their health conditions, worksite health promotion (WHP) has become necessary. Over the past three decades, many WHP studies have focused on how to implement effective intervention and measure the effectiveness of WHP and the cost-effectiveness of WHP programs. However, the overweight and obesity rates are still going up all over the world (3), and the evidence of the effectiveness of WHP program is also inconsistent. To clarify the factors which influence the successfulness of WHP program, more studies relating to the health behaviors, barriers, promoters, and supporting environment were created. In recent years, there is one issue having received attention gradually: Workplace health culture.

Culture is an abstract concept which describes employees' attitudes and behaviors, and norms that is very ethnically and geographically specific, and it will affect specific behaviors $(4,5)$. Organizational culture is an important element of business management and there are kinds of cultures in different dimensions, including safety culture and healthy culture. A related concept is the "worksite culture of health" which includes the gamut of organizational factors that work to encourage healthy lifestyle choices (6-9). Currently, safety culture is a mature dimension and has received attention earlier than health culture (10-13). Many companies have created their 
safety culture to keep employees' safe, reduce the costs associated with work-related accident, and enhance their corporate image. As the comprehensive occupational safety program can benefit the work of preventing injury, successful workplace wellness programs must be tailored to employees' health needs and wishes as well as complementing each organization's unique culture $(9,14)$. For healthy behaviors, culture acts as an interpersonal force to increase or decrease motivation like self-determination and self-efficacy $(15,16)$. This means that just as the safety culture and employee safety are related and important, if we want to effectively promote the healthy lifestyle of employees, healthy culture is inevitably a very important issue of WHP intervention, and it is necessary creating workplace health culture for implementing more comprehensive and better effectiveness worksite health promotion in the future.

The health culture concept is understood to be a set of core attributes engendered by the interaction of social and organizational systems that reflect the values, assumptions, expectations, and definitions of workers that in turn affect the way workers think, feel, and behave with regard to personal and group health $(17,18)$. Until now, there are not many studies on health culture, and only a few tools are available to measure this construct; at the same time, all of them have different definitions of the components of health culture $(7,19-22)$. Although we are not sure whether the existing health culture measurement tools are applicable to Taiwan, some items related to local regulations or habits may reduce the applicability of these tools, and some questions do not apply to Taiwan's health culture assessment. Therefore, the development of a more extensive tool can not only help Taiwan's work of WHP, but also contribute to the promotion of this study issue. The purpose of this study was to develop and validate Workplace Health Culture Scale (WHCS) to improve the work of WHP in Taiwan.

\section{METHODS}

This study focused on developing and validating the WHCS between August 2017 and June 2019, and it was approved by the Institutional Review Board (IRB) of Taipei Medical University and budget supplements were granted by the Ministry of Science and Technology Taiwan. In this study, three phases were carried out to develop WHCS: (1) reviewing literature and defining domain, (2) item generation, (3) validation test. Data were collected from six companies in Northern Taiwan between June 2018 and December 2018.

\section{Development of Workplace Health Scale and the Definition of Domains}

First, we organized an expert group to integrate literature and define domains. The expert group consisted of seven health and psychology professionals, including one WHP and health behavior expert, one WHP and occupational safety and health (OHS) expert, one Occupational Safety and Health Administration supervisor, one workplace health productivity expert, one global health expert, one industrial and organizational psychologist, and one statistician who has experience in scale development. In addition, the industrial and organizational psychologist has a good experience in developing the safety culture scale (23-25). In the first session, we integrated the definition and framework of workplace health culture which was mainly collected from Allen (6), Aldana (26), and Kent's (18) study. Table 1 contains a list of our domain definitions. According to the definition of culture, the expert group believed the WHCS items would need to focus on employees' cognition, attitudes, and feelings toward workplace health promotion. Therefore, we generated eight domains as follows: (1) Supporting Environment, (2) Health Policy, (3) Health Climate, (4) Peer Support, (5) Supervisor Support and Role Modeling, (6) Health Involvement, (7) Personal Value, and (8) Common Value.

Then we generated items to these domains with a total of 67 items. Every item began with the heading "I think..." or "My colleagues and I feel that..." to reflect the employees' attitudes and feelings. We recruited additional two WHP and OHS experts to join the expert group and to check the feasibility and content validity based on the five-point Likert scale and open-ended feedback. Items remained on the list were according to the four criteria: (1) fitness $\geqq 3.0$ points, (2) importance $\geqq$ 3.0 points, (3) description clarity $\geqq 3.0$ points, and (4) experts' specific amendments.

Finally, there were 65 items remaining on the list with descriptions on some items being corrected. The supporting environment contained six items, including the physical activity/healthy diet/psychological health/health risk assessment/health management system environment or service that made employees feel health was valued by the employer; the health policy contained 10 items, including the attitude of whether the health policies could be effectively implemented and carried out; the health climate contained 10 items, including five

TABLE 1 | Definitions of the workplace health culture scale (first edition).

\begin{tabular}{|c|c|}
\hline Domains & Definition \\
\hline $\begin{array}{l}\text { Supporting } \\
\text { environment }\end{array}$ & $\begin{array}{l}\text { The feelings and attitudes about the physical } \\
\text { environment of sports, diets, and psychological health, } \\
\text { and the importance of the company's emphasis on the } \\
\text { employees' health promotion issues }\end{array}$ \\
\hline Health policy & $\begin{array}{l}\text { Employees' attitudes toward company policies on health } \\
\text { promotion, including physical activities, healthy diets, } \\
\text { psychological health, and work-life balance }\end{array}$ \\
\hline Health climate & $\begin{array}{l}\text { Employees' attitudes and feelings toward health } \\
\text { promotion within the company }\end{array}$ \\
\hline Peer support & $\begin{array}{l}\text { Employees' feelings and attitudes about encouraging } \\
\text { each other to have a healthy lifestyle and even forming } \\
\text { groups to promote health }\end{array}$ \\
\hline $\begin{array}{l}\text { Supervisor support } \\
\text { and role modeling }\end{array}$ & $\begin{array}{l}\text { Employees' feelings about supervisors' attitudes toward } \\
\text { health promotion, and the extent to which the } \\
\text { supervisors play the role models }\end{array}$ \\
\hline Health involvement & $\begin{array}{l}\text { Employees' attitudes, behaviors, and responsibilities on } \\
\text { the WHP activities they participate in }\end{array}$ \\
\hline Personal value & $\begin{array}{l}\text { Individual's beliefs, attitudes, and cognition toward health } \\
\text { promotion }\end{array}$ \\
\hline Common value & $\begin{array}{l}\text { The common beliefs and attitudes toward health } \\
\text { promotion }\end{array}$ \\
\hline
\end{tabular}


items on which the employees felt about a specific health climate in the company (e.g., physical activity climate), and five items on which the employees felt about the supervisor's attitudes of a specific healthy lifestyle and health behavior; the peer support contained eight items which looked at the employees' feelings and attitudes about encouraging each other to have a healthy lifestyle; the supervisor support and role modeling contained nine items, including two items about the CEO's healthy lifestyle role modeling, two items about the direct supervisors' role modeling, and five items about the direct supervisors' support on healthy lifestyle; the health involvement contained eight items which looked at the employees' attitudes on the healthy activities they participated in; the personal value contained five items which examined employees' personal beliefs and attitudes toward WHP; and the common value contained 10 items which looked into the employees' common beliefs and attitudes toward health promotion. Considering the original survey items are constructed in Chinese language with the rigor of translation in the context, for more detailed information about specific items, please contact the author(s).

After the completion of the WHCS first edition, we started inviting companies for validity test. Considering the need of representative and diversified samples, we recruited six companies from three different industries and company sizes. Construct validity and composite reliability were assessed to verify our health culture framework and to determine the appropriateness of items by both exploratory factor analysis and confirmatory factor analysis. We also tested the discriminant validity among companies and the internal consistency of the WHCS's final version.

\section{Samples}

Six companies were recruited from Northern Taiwan, including the large-sized bank A, the small-sized bank B, the large-sized manufacturers $\mathrm{C}$ and $\mathrm{D}$, the large-sized technology company $\mathrm{E}$, and the medium-sized retail and wholesale company $\mathrm{F}$. Engagement in WHP varied among the companies (e.g., in terms of the issues they address, level of comprehensiveness, and maturity of program). Three companies were awarded the 2018 Health Promotion Administration Ministry of Health and Welfare's WHP prize (Companies C, E, and F), which is the highest official certification and honorary award a company can earn for workplace health promotion in Taiwan, and it has been in operation for 12 years. In this study, the participating enterprises were recruited from a pool of the certified companies. We invited and collected samples from each of the small and medium-sized enterprises, aiming for at least $50 \%$ participating rate. Considering a greater number of employees in the technology company $\mathrm{E}(\sim 6,000$ employees $)$ than other companies in this study, we collected 1,000 samples from the company $\mathrm{E}$ to ensure an adequate representation. Between June and December 2018, we sent online questionnaire to the target companies and had the assistance from the health promotion leaders of these companies in the promotion and recruitment, and participants were rewarded $50 \mathrm{New}$ Taiwan dollars for each questionnaire. Out of the 2,575 total survey respondents, 2,431 completed the questionnaire. This represented $\sim 16.4-97.8 \%$ of the eligible employee population, with small-size company (B) having relatively higher participation rates and the large-size company (E) the lowest. We did not separate domains in this survey but combined all the 65 items into one questionnaire.

\section{Statistical Analysis}

The validation test included exploratory factor analysis and confirmatory factor analysis. Before the factor analysis, we adjusted our sample size. Considering the recommendations of sample size for conducting factor analysis (27), we decided to use 10 times the number of questions for exploratory factor analysis and confirmatory factor analysis. We randomly extracted 300 samples from company $\mathrm{E}$ and combined with other samples, and then we randomly extracted 650 samples from this large sample pool $(n=2,431)$ for analysis. We confirmed that the randomly extracted samples were not significantly different from the original sample demographic characteristics.

The exploratory factor analysis was used for reducing the number of items. We used the principal component factor analysis with the varimax rotation and eigenvalue criterion $>1.0$ to detect the latent variable. Before analysis, we confirmed the feasibility of factor analysis by Kaiser-Meyer-Olkin test (KMO) and Bartlett's test of sphericity. Then, items with factor loading $<0.50$, cross-loading $>0.40$, or communalities $<0.30$ were eliminated $(28,29)$. In addition, every latent variable had to have at least three factors. The exploratory factor analysis was analyzed at a 95\% significance level and conducted using PASW 22.0 software for Windows (SPSS, Chicago, IL).

After the factor analysis, we performed the confirmatory factor analysis to build the conceptual model and compared it with the original model (as Table 1 list) to establish construct validity and reliability of WHCS. Before full model building, every latent variable collected from confirmatory factor analysis was tested separately for the model fitness to detect any unsuitable item. The following criteria of model fitness were used: root mean square error of approximation (RMSEA) $<0.08$ (and 0.05 or lower should be better), $\chi^{2} / \mathrm{df}<5$, standardized root mean square residual (SRMR) $<0.08$, comparative fit index $(\mathrm{CFI})$ $>0.90$, Tucker-Lewis index (TLI) $>0.90$ (30-33). In addition, the composite reliability (CR) needed to be $>0.7$ for appropriate construct reliability (34), and average variance extracted (AVE) had to be $>0.5$ for appropriate convergent validity (35). We used AMOS 20.0 software to conduct confirmatory factor analysis (Chicago, IL).

Finally, we conducted ANOVA test for the six companies with the final version of WHSC to detect the discriminant validity of different degrees of WHP and the companies. The Cronbach's $\alpha$ was also tested for appropriate content reliability (36), and the threshold was 0.70 or greater. The test was analyzed at a $95 \%$ significance level $(P<0.05)$.

\section{RESULTS}

\section{Demographics}

The demographic characteristics of the study samples $(N=$ 2,431) are listed in Table 2. The total number of workers of these six companies ranged from 188 to 6,270 . The two 
TABLE 2 | Demographic characteristics of samples.

\begin{tabular}{|c|c|c|c|c|c|c|}
\hline & \multicolumn{6}{|c|}{$\begin{array}{l}\text { Companies } \\
\qquad(\%)\end{array}$} \\
\hline & $\begin{array}{c}\text { Bank A } \\
(n=267)\end{array}$ & $\begin{array}{c}\text { Bank B } \\
(n=139)\end{array}$ & $\begin{array}{c}\text { Manufactory C } \\
(n=264)\end{array}$ & $\begin{array}{l}\text { Manufactory D } \\
\quad(n=328)\end{array}$ & $\begin{array}{l}\text { Technology company } E \\
\qquad(n=1,029)\end{array}$ & $\begin{array}{l}\text { Wholesale retailer F } \\
\qquad(n=322)\end{array}$ \\
\hline \multicolumn{7}{|l|}{ Gender } \\
\hline Male & $128(47.9)$ & $47(33.8)$ & $206(78.0)$ & $166(50.6)$ & 637 (61.9) & 207 (64.3) \\
\hline Lower than junior high school & $0(0.0)$ & $3(2.2)$ & $1(0.3)$ & $10(3.1)$ & $2(0.2)$ & $0(0.0)$ \\
\hline Senior high school & $11(4.2)$ & 15 (10.9) & $53(20.2)$ & $40(12.2)$ & $6(0.6)$ & $35(11.0)$ \\
\hline University & $194(74.3)$ & $68(49.7)$ & $174(66.2)$ & $210(64.2)$ & 407 (39.6) & $222(70.1)$ \\
\hline Master's degree or higher & $56(21.5)$ & $51(37.2)$ & 35 (13.3) & 67 (20.5) & 614 (59.6) & $60(18.9)$ \\
\hline \multicolumn{7}{|l|}{ Age, years } \\
\hline $50-64$ & $40(15.3)$ & $48(36.1)$ & $89(33.8)$ & 89 (27.3) & $13(1.3)$ & $45(14.2)$ \\
\hline 65 or higher & $3(1.1)$ & $1(0.8)$ & $0(0.0)$ & $1(0.3)$ & $0(0.0)$ & $0(0.0)$ \\
\hline Age, years (Mean \pm SD) & $\begin{array}{c}39.6 \pm \\
10.13\end{array}$ & $\begin{array}{c}42.5 \pm \\
12.49\end{array}$ & $43.6 \pm 9.64$ & $42.6 \pm 10.19$ & $37.7 \pm 9.68$ & $39.8 \pm 8.45$ \\
\hline Seniority, years (Mean \pm SD) & $\begin{array}{c}13.2 \pm \\
10.14\end{array}$ & $\begin{array}{c}13.1 \pm \\
11.82\end{array}$ & $18.1 \pm 9.81$ & $15.2 \pm 11.48$ & $5.5 \pm 4.55$ & $8.9 \pm 7.15$ \\
\hline Total number of workers & 923 & 188 & 3,229 & 1,204 & 6,270 & 323 \\
\hline
\end{tabular}

SD, standard deviation.

banks had significantly higher proportion of female workers. The technology company had the highest proportion of employees with a master's degree or higher education level (59.7\%), the lowest average age (37.7 \pm 9.68 years), and the lowest average seniority (5.5 \pm 4.55 years). In general, most of the samples had an educational level with at least a bachelor's degree.

\section{Exploratory Factor Analysis}

The first exploratory factor analysis produced 11 latent variables, accounting for $68.57 \%$ total variance. The KMO test of sampling adequacy was 0.967 and Bartlett's test for sphericity was highly significant $(p<0.001)$. The original 65 items were gradually eliminated according to their factor loading and cross-loading criteria, and eventually 38 items remained. There were 27 items eliminated as follows: 11 items had factor loading lower than $0.50,12$ items had cross-factor loading higher than 0.40 , and two latent variables had only two items of each (and only $<2 \%$ total explained variance). The two eliminated latent variables were separated from the "Supporting Environment" domain and the "Peer Support" domain. The factor analysis of the rest of the 38 items produced seven latent variables, accounting for $63.19 \%$ total variance. Most of the items remained in the original domains except Q15, which was classified as "Health climate" from "Health policy." Therefore, we did not change any domain's label.

\section{Confirmatory Factor Analysis}

The confirmatory factor analysis tested each of the seven domains after the exploratory factor analysis test. However, only four domains could be analyzed since the other three domains had only three items each (just-identified). The first domain- "Health Climate"-which had the highest total explained variance in exploratory factor analysis had 11 items. We eliminated Q15, Q17, Q19, and Q24 since they had higher modification index (M.I.) value and high significant correlation with other items. The second domain- "Common Value"-had seven items. We eliminated Q58 for the same reason. The third domain"Supervisor Support and Role Modeling"-had five items, and we eliminated Q35 since it significant correlated to Q37 and Q39, and it had a high M.I. value. The fourth domain- "Supporting Environment"-had four items, and it was the only domain that was eliminated because Q1 and Q3, Q2 and Q4 had very high significant correlation with each other that lacked enough model fit. The fifth domain- "Health Policy"-had five items. We eliminated Q9 due to its high M.I. value.

Six domains were constructed from the remaining 25 items, and the total explained variance was $69.64 \%$ (Table 3). All of the domains could meet the criteria of CR and AVE, and the Cronbach's $\alpha$ was $0.804-0.919$. Table 4 showed the model fit and the correlations among the domains. The two domains- "Health Climate" and "Supervisor Support and Role Modeling"-had worse model fit than others since each item within the domains had a certain degree of correlation (Health Climate had RMSEA $=0.075, \chi^{2} / \mathrm{df}=4.879$, Supervisor Support and Role Modeling 
TABLE 3 | Factor loadings for 25-items workplace health culture scale $(N=650)$.

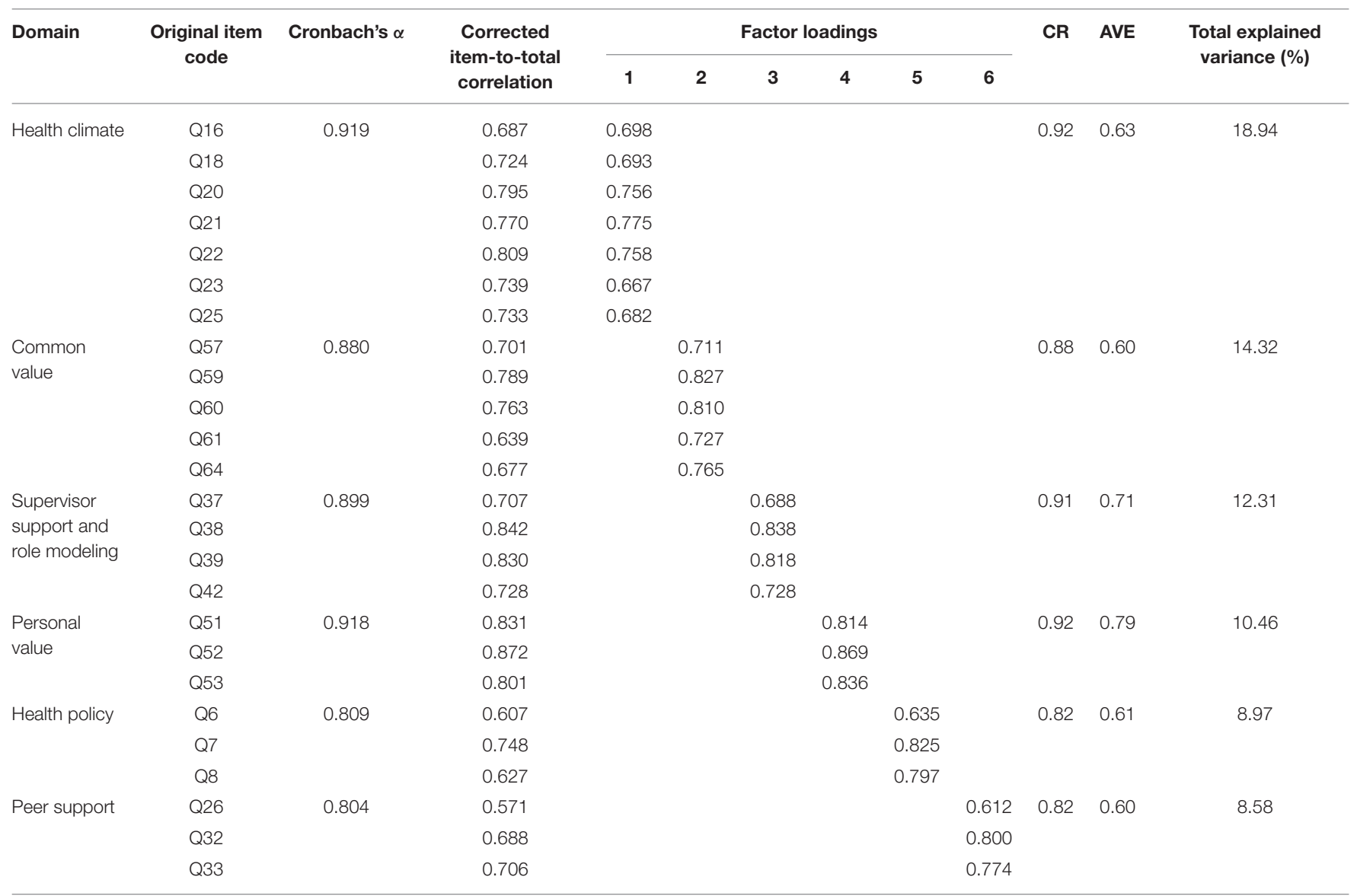

CR, composite reliability; AVE, average variance extracted.

TABLE 4 | Corrections among constructs.

\begin{tabular}{|c|c|c|c|c|c|c|c|c|c|c|}
\hline \multirow[t]{2}{*}{ Domain } & \multicolumn{4}{|c|}{ Model fit } & \multicolumn{6}{|c|}{ Correlations } \\
\hline & RMSEA & $\chi^{2} / \mathrm{df}$ & SRMR & CFI & & & & & & \\
\hline Health climate & 0.075 & 4.879 & 0.023 & 0.982 & - & & & & & \\
\hline Common value & 0.048 & 2.611 & 0.014 & 0.995 & $0.458^{\star \star}$ & - & & & & \\
\hline Supervisor support and role modeling & 0.079 & 5.275 & 0.016 & 0.995 & $0.637^{\star \star}$ & $0.474^{\star \star}$ & - & & & \\
\hline Personal value & - & - & - & - & $0.499^{\star \star}$ & $0.479^{\star \star}$ & $0.514^{\star \star}$ & - & & \\
\hline Health policy & - & - & - & - & $0.641^{\star \star}$ & $0.306^{\star \star}$ & $0.403^{\star \star}$ & $0.347^{\star *}$ & - & \\
\hline Peer support & - & - & - & - & $0.585^{\star \star}$ & $0.512^{\star \star}$ & $0.552^{\star *}$ & $0.433^{\star *}$ & $0.431^{\star \star}$ & - \\
\hline Full model & 0.059 & 3.412 & 0.060 & & & & & & & \\
\hline
\end{tabular}

RMSEA, root mean square error of approximation; SRMR, standardized root mean square residual; CFI, comparative fit index.

${ }^{\star \star} p<0.01$.

had RMSEA $\left.=0.079, \chi^{2} / \mathrm{df}=5.275\right)$. The full model exhibited enough fit statistics (RMSEA $=0.059, \chi^{2} / \mathrm{df}=3.412, \mathrm{SRMR}=$ 0.060 , CFI $=0.952$, GFI $=0.917$, TLI $=0.938)$. The model fit did not have significant improvement when we eliminated some items with a relatively high M.I. value in the full model (e.g., Q16 and Q42); therefore, Q16 and Q42 were retained. Comparing to our original domain definition, two domains were eliminated (Supporting Environment and Health Involvement), but most items could be correctly classified under the original domain, hence we believe that this scale has sufficient construct validity. All of the domains' Cronbach's alpha were above 0.90 .

The final model had good discriminant validity (Table 5). All of the domains and the total score had significant differences among the 6 companies. In general, those companies which won the WHP prize in 2018 (Company C, E, and F) had significant higher points than others, but the small bank $\mathrm{B}$ had the highest 


\begin{tabular}{|c|c|c|c|c|c|c|c|}
\hline & \multicolumn{7}{|c|}{$\begin{array}{l}\text { Companies } \\
\text { (Mean } \pm \text { SD) }\end{array}$} \\
\hline & $\begin{array}{c}\text { Bank A } \\
(n=262)\end{array}$ & $\begin{array}{c}\text { Bank B } \\
(n=134)\end{array}$ & $\begin{array}{l}\text { Manufactory C } \\
\qquad(n=263)\end{array}$ & $\begin{array}{l}\text { Manufactory D } \\
\qquad(n=326)\end{array}$ & $\begin{array}{l}\text { Technology company E } \\
\qquad(n=1029)\end{array}$ & $\begin{array}{l}\text { Wholesale retailer F } \\
\qquad(n=316)\end{array}$ & $p$ value \\
\hline Health climate & $21.3 \pm 5.70$ & $24.8 \pm 4.69$ & $24.9 \pm 4.79$ & $23.2 \pm 4.76$ & $24.3 \pm 4.49$ & $27.2 \pm 4.16$ & $<0.001^{\star \star}$ \\
\hline Common value & $19.9 \pm 2.61$ & $21.1 \pm 2.54$ & $21.0 \pm 2.19$ & $20.5 \pm 2.36$ & $20.5 \pm 2.59$ & $20.8 \pm 2.56$ & $<0.001^{\star \star}$ \\
\hline Supervisor support and role modeling & $13.3 \pm 3.22$ & $14.5 \pm 3.04$ & $14.6 \pm 2.53$ & $14.4 \pm 2.64$ & $14.8 \pm 2.74$ & $15.3 \pm 2.68$ & $<0.001^{\star \star}$ \\
\hline Personal value & $10.4 \pm 2.23$ & $10.9 \pm 2.16$ & $11.3 \pm 1.93$ & $10.7 \pm 1.88$ & $10.9 \pm 2.08$ & $11.2 \pm 2.05$ & $<0.001^{\star \star}$ \\
\hline Health policy & $8.1 \pm 4.03$ & $8.9 \pm 3.66$ & $10.0 \pm 3.24$ & $8.2 \pm 4.12$ & $9.3 \pm 3.22$ & $11.0 \pm 2.92$ & $<0.001^{\star *}$ \\
\hline Peer support & $10.5 \pm 2.07$ & $12.1 \pm 1.51$ & $11.2 \pm 1.86$ & $11.0 \pm 1.91$ & $11.2 \pm 1.99$ & $11.3 \pm 1.78$ & $<0.001^{\star *}$ \\
\hline Total score & $83.5 \pm 14.6$ & $92.4 \pm 13.4$ & $93.1 \pm 12.90$ & $88.1 \pm 12.67$ & $91.1 \pm 12.68$ & $96.7 \pm 12.49$ & $<0.001^{\star \star}$ \\
\hline
\end{tabular}

$S D$, standard deviation.

${ }^{\star \star} p<0.01$.

peer support point. Therefore, the final version of WHCS has six domains-Health Climate, Common Value, Supervisor Support and Role Modeling, Peer Support, Personal Value and Common Value-and 25 items in total.

\section{DISCUSSION}

This is the first Chinese workplace health culture audit with appropriate development and validation work. In this study, we developed and validated the WHCS, and it had appropriate construct validity, content validity, discriminant validity, composite reliability, and internal consistency. This scale was developed based on several current workplace health culture and audit literature, and we believe it can appropriately reflect the workplace health culture and can be used for the improvement of WHP.

Considering our goal was to measure the workplace health culture and none of the existing tools could truly meet our needs in addressing the construct of interest, we saw the need of creating a new tool which is the frame and design of the "culture" definition from our point of view and the quality of the existing tools. Before we developed WHCS, we compared all the current health culture measurement tools $(6,7,18,20,21)$ and took all the current health culture frame and theory into consideration $(17,22,26,37,38)$. Health culture is a collective cognition and attitude, which is built on the individual's subjective and abstractive attitude, values, and beliefs to health. However, some of current health tools do not meet our definition, e.g., Jia's Chinese workplace health culture scale (21) and Kent's Culture of health scale (38). Jia's Chinese Workplace Health Culture scale had a lot of items related to direct supervisor's health behaviors (e.g., smoking, drinking, exercise) and the support and encouragement from the direct supervisor and family to lead a healthy lifestyle; it was not about the workplace health culture but the employees' cognition and attitude. Kent's Culture of health scale consisted of two parts: internal and external culture of health, and this scale was more likely a culture checklist rather than a personal questionnaire. For example, it asked the number of employees who were given health education in the past 12 months, whether the organization had a health promotion strategic plan, and it contained some openended questions to explore the organizational commitment and volunteerism. Aldana's review study pointed out that several health culture measurement tools developed before 2012 had some shortcomings, which were verified to be less relevant to health (19) or lacked evidence of reliability and validity (39). In addition, we also excluded those scales related to "health climate" since it was not the same as culture. Organizational culture and climate are not the same thing (40), climate has narrower concept than culture; however, both of them focus on the shared perception, values, and beliefs rather than the actual environment evaluation. It means the health culture measurement is not the evaluation of the degree of the accessibility or applicability in the health policy and physical and psychological environment, nor is it about the feeling of employees toward them. Finally, after checking the LHCA and Kwon's Culture of Health scale $(\mathrm{COH})$ and considering that the translation and modification of the questionnaire would result in subtle variation in the semantics and that some questions might be irrelevant to the regulations in Taiwan, we finally decided to develop a new scale.

In general, WHCS has six domains and 25 items. Comparing to our original domain definition, only two domains were eliminated, and most items could be classified under the original domain. It might mean that our item design was appropriate and close to the original definition. In WHCS, we put more emphasis on the concept of collective cognition and attitude, so we excluded the investigation about the physical normative and physical environment. Comparing to Allen's Lifegain framework and Lifegain Health Culture Audit (LHCA) $(6,7)$, WHCS does not include the "normative" domain, and the domain of values is divided into personal and common values. In addition, the supporting environment and health policy domain also focus on "whether these supporting material works" instead of "the availability of materials," and it is the most obvious difference from the LHCA. Comparing to $\mathrm{COH}$ (41), which separates the definition of the supporting environment into two parts- "environment components" and "culture components," our domains and items are closer to the "culture components" part. Considering the "organizational culture" was defined as a kind of "shared basic assumptions" 
(37), the workplace health culture should have similar definitions and characteristics. In general, since the definitions of health culture are inconsistent until now, the criterion validity might not be appropriate to the development of workplace health culture tools.

The exclusion of the domain about support environment may be quite reasonable, and it's not just because the model fits problem. In addition to the environment evaluation might not close to the culture definition, there might be another explanation. Until now, there have been many intervention studies in WHP that adopted supporting environment interventions alone or combined with other intervention, but the evidence of effectiveness is still inconsistent. Some studies have found that adopting environmental interventions alone is completely ineffective in improving employees' health behaviors and health status (42-45). However, combined with other behavioral interventions, environmental intervention can help to promote the effectiveness of WHP $(46,47)$. Therefore, most countries now encourage comprehensive WHP as much as possible. Such research evidence may represent that the supporting environment's influence on changing health attitudes or behaviors is more indirect than other domain of health culture or direct work of behavioral intervention, and this might explain why this domain was excluded in this study.

Another domain excluded in this study is "Health Involvement." Health involvement was related to employees' attitudes, behaviors, and responsibilities they had participating in the WHP activities, and we assumed it might be affected by the quality and comprehensiveness of WHP, which were different among the six workplaces. It might cause the cyclical interference of health involvement and its impact factor. For example, there were more companies believing that employees' health was entirely their own responsibility, especially for the small and medium-sized enterprises $(48,49)$, and it would affect employees' attitudes and health involvement in participation $(50,51)$. Although it was more complicated than other domains and was excluded from the WHCS, we believe that it is still very important and there should be more in-depth research with regard to worksite health culture.

Although we excluded the investigation of physical environment of WHCS, it might be an interesting issue to be studied in the future. In this study, we noticed the health culture might not directly associate with the business size (Table 5). The small and midsized business might have lower resources to WHP program; however, recent studies have shown that the effectiveness of WHP does not entirely depend on the size of the company (52). For example, small businesses might be more likely to shape the peer support in health. On the contrary, large enterprises might not necessarily create a better health culture even if they have the ability to invest more physical materials and resources in the WHP. The question "What kind of WHP investment might shape the health culture more effectively?", or "Which work of WHP might evoke a positive attitude and cognition to health and build supporting climate for each other?" (e.g., how long, to whom, and to what degree the comprehensiveness of the WHP intervention is suitable to change the culture?) might be the most important field to the WHP in the future.

Our study has several strengths. First, we conducted a complete review of the definition and related literature on organizational culture and health culture and compared existing measurement tools. It seems that not all of the health culture measurement tools are in compliance with our definition of culture nor can they provide us with suitable measurement. Our second strength was that we filled in the gap that only few tools had enough comprehensive structure. This strength might increase the applicability of the tool outside of Taiwan since most of the items focus on the subjective attitudes and employees' cognition and less on objective policies and environment at the substantive level, but we still believe that this requires rigorous verification and testing. In addition, though the final version of WHC consists of only 25 items, it is still good model fit that we believe it yielded sound response in this study.

The limitations of this study could be used to build future research. First, an effective, validated representation of WHCS should incorporate wider varieties of industries across different sizes of enterprises, and it should also include confirmatory factor analysis and model fit tests. Second, we would take into consideration of assigning different weight to each domain of WHCS in the future since it has an unbalanced number of items in each domain. Therefore, our next study will focus on the extensive validation of this tool and its relevance to the environment, employees' health behaviors, demographic characteristics and other factors that may influence health culture, and the association to the health risk.

\section{CONCLUSIONS}

In this study, we developed and validated the WHCS, and the results of this study indicated the WHCS has appropriate reliability and validity. WHCS is suitable for measuring employees' attitudes, cognition, and feelings of a healthy workplace for improving the WHP in Taiwan. Based on the limitations and strengths of this study, we suggest that more studies about reliability and validity of WHCS and the correlation between WHCS and other WHP measuring indicators (e.g., personal health behavior and physical and psychological environment) are needed.

\section{DATA AVAILABILITY STATEMENT}

The raw data supporting the conclusions of this manuscript will be made available by the authors, without undue reservation, to any qualified researcher.

\section{ETHICS STATEMENT}

Taipei Medical University- Joint Institutional Review Board Committee waived the requirement for written informed consent for participants in this study due to the questionnaire for this study was completely anonymous 
and de-linked, and the written informed consent was the only source that could link to the respondent's individual. In addition, the questionnaire is distributed by the research team, or the online questionnaire is used, and the content of the questionnaire has the minimum personal risk, in accordance with the national legislation and the institutional requirements.

\section{AUTHOR CONTRIBUTIONS}

Y-TC, R-YC, F-JT, C-CK, and C-YY participated in the conception, design of the study, and scale development. Y-TC participated in acquisition of data. Y-TC, R-YC,

\section{REFERENCES}

1. Baicker K, Cutler D, Song ZR. Workplace wellness programs can generate savings. Health Aff. (2010) 29:304-11. doi: 10.1377/hlthaff.2009.0626

2. Haskell WL, Lee IM, Pate RR, Powell KE, Blair SN, Franklin BA, et al. Physical activity and public health - Updated recommendation for adults from the American college of sports medicine and the American heart association. Circulation. (2007) 116:1081-93. doi: 10.1161/CIRCULATIONAHA.107.185649

3. Organization, WHO. Obesity and Overweight factsheet from the WHO. Health (2017). Available online at: https://www.who.int/news-room/factsheets/detail/obesity-and-overweight

4. Kroeber AL, Kluckhohn C. Culture: A Critical Review of Concepts and Definitions. Wiley for Wesleyan University (1964).

5. Schein EH. Organizational Culture, Vol. 45. American Psychological Association (1990).

6. Allen RF, Linde S. Lifegain: The Exciting New Program That Will Change Your Health-and Your Life. New York, NY: Appleton-Century-Crofts (1981).

7. Golaszewski T, Hoebbel C, Crossley J, Foley G, Dorn J. The reliability and validity of an organizational health culture audit. Am J Health Stud. (2008) 23:116-23.

8. Berry LL, Mirabito AM, Baun WB, What's the hard return on employee wellness programs? Harv Bus Rev. (2010) 88:104-12, 142.

9. Terry PE, Seaverson EL, Grossmeier J, Anderson DR. Association between nine quality components and superior worksite health management program results. J Occup Environ Med. (2008) 50:633-41. doi: 10.1097/JOM.0b013e31817e7clc

10. Cox SJ, Cheyne AJT. Assessing safety culture in offshore environments. Saf Sci. (2000) 34:111-29. doi: 10.1016/S0925-7535(00)00009-6

11. Short JF. The challenger launch decision: risky technology, culture, and deviance at NASA - Vaughan, D. Contemp Sociol J Rev. (1996) 25:7279. doi: $10.2307 / 2077251$

12. Pidgeon N. Safety culture: key theoretical issues. Work Stress. (1998) 12:20216. doi: $10.1080 / 02678379808256862$

13. Cooper MD. Towards a model of safety culture. Saf Sci. (2000) 36:11136. doi: 10.1016/S0925-7535(00)00035-7

14. Goetzel RZ, Henke RM, Benevent R, Tabrizi MJ, Kent KB, Smith KJ, et al. The predictive validity of the HERO Scorecard in determining future health care cost and risk trends. J Occup Environ Med. (2014) 56:13644. doi: 10.1097/JOM.0000000000000081

15. Deci EL. Self-determination theory and education. Cesk Psychol. (1994) 38:420-6.

16. Deci EL, Ryan RM. The theory of self-determination of motivation and its relevance to pedagogics. Z Padagogik. (1993) 39:223-38.

17. Allen J. Building supportive cultural environments. In: O'Donnell MP, eds. Health Promotion in the Workplace. Albany, NY: Delmar Publishers, Inc. (2002)

18. Kent K, Goetzel RZ, Roemer EC, Prasad A, Freundlich N. Promoting healthy workplaces by building cultures of health and and C-YY performed the statistical analysis and drafted the manuscript. All authors read and approved the final manuscript.

\section{FUNDING}

This study was funded by the Ministry of Science and Technology (MOST) of Taiwan (MOST 106-2314-B-038-041).

\section{ACKNOWLEDGMENTS}

The authors would like to thank the participants in this study for their time and efforts. applying strategic communications. J Occup Environ Med. (2016) 58:114-22. doi: 10.1097/JOM.0000000000000629

19. Basen-Engquist K, Hudmon KS, Tripp M, Chamberlain R. Worksite health and safety climate: scale development and effects of a health promotion intervention. Prev Med. (1998) 27:111-9. doi: 10.1006/pmed.1997.0253

20. Smith DR, Guidotti TL, Kwon Y, Marzec ML. Does worksite culture of health $(\mathrm{CoH})$ matter to employees? Empirical evidence using job-related metrics. $J$ Occup Environ Med. (2016) 58:448-54. doi: 10.1097/JOM.0000000000000724

21. Jia Y, Gao J, Dai J, Zheng P, Fu H. Associations between health culture, health behaviors, and health-related outcomes: a cross-sectional study. PLoS ONE. (2017) 12:e0178644. doi: 10.1371/journal.pone.0178644

22. Crimmins TJ, Halberg J. Measuring success in creating a "culture of health". $J$ Occup Environ Med. (2009) 51:351-5. doi: 10.1097/JOM.0b013e318196a8e6

23. Tsay C-YJ, Kuo C-C, Chao C-J, Drury CG, Hsiao Y-L. Safety culture evaluation in China Airlines: a preliminary study. In: International Conference on Engineering Psychology and Cognitive Ergonomics. Taoyuan: Springer (2014).

24. Kuo C-C, Tsaur C-C, Kao F-H. Perceived control and work safety: the mediating role of safety culture. J Occup Saf Health. (2010) 18:95-110. doi: 10.7005/JOSH.201003.0095

25. Kuo C-C, Tsaur C-C, Chang Y-Y. The study of norm of safety culture questionary in construction industry of Taiwan. J Occup Saf Health. (2006) 15:91-103.

26. Aldana SG, Anderson DR, Adams TB, Whitmer RW, Merrill RM, George V, et al. A review of the knowledge base on healthy worksite culture. J Occup Environ Med. (2012) 54:414-9. doi: 10.1097/JOM.0b013e31824be25f

27. Howe GR, Anderson TW, Rubin H. Statistical inference in factor analysis. In: Proceedings of the Third Berkeley Symposium on Mathematical Statistics and Probability (1956) Okland, CL: University of California.

28. DeVellis RF. Scale Development: Theory and Applications, Vol. 26. Thousand Oaks, CA Sage Publications (2016).

29. Fabrigar RL, Wegener DT, MacCallum RC, Strahan EJ. Evaluating the use of exploratory factor analysis in psychological research. Psychol Methods. (1999) 4:272-99. doi: 10.1037//1082-989X.4.3.272

30. Bentler PM. Comparative fit indexes in structural models. Psychol Bull. (1990) 107:238-46. doi: 10.1037//0033-2909.107.2.238

31. McDonald RP, Marsh HW. Choosing a multivariate model: noncentrality and goodness of fit. Psychol Bull. (1990) 107:247. doi: 10.1037/0033-2909.107. 2.247

32. Mulaik SA, James LR, Van Alstine J, Bennett N, Lind S, Stilwell CD. Evaluation of goodness-of-fit indices for structural equation models. Psychol bulletin. (1989) 105:430. doi: 10.1037/0033-2909.105.3.430

33. Hu LT, Bentler PM. Cutoff criteria for fit indexes in covariance structure analysis: conventional criteria versus new alternatives. Struct Eq Model Multidiscipl J. (1999) 6:1-55. doi: 10.1080/10705519909540118

34. Hair JF, Black B, Babin B, Anderson RE, Tatham RL. Multivariate Data Analysis, Vol. 6. Upper Saddle River, NJ: Pearson Prentice Hall (2006).

35. Fornell C, Larcker DF. Evaluating structural equation models with unobservable variables and measurement error. J Mark Res. (1981) 18:3950. doi: $10.1177 / 002224378101800104$ 
36. Nunnally JC, Bernstein I. Psychometric Theory (McGraw-Hill Series in Psychology), Vol. 3. New York, NY: McGraw-Hill (1994).

37. Schein EH. Organizational Culture and Leadership, Vol. 2. San Francisco, CL: John Wiley \& Sons (2010).

38. Kent KB, Goetzel RZ, Roemer EC, McCleary K, Henke RM, Head MA, et al. Developing two culture of health measurement tools: examining employers' efforts to influence population health inside and outside company walls. J Occup Environ Med. (2018) 60:1087-97. doi: 10.1097/JOM.0000000000001438

39. Ribisl KM, Reischl TM, Ribisl KM, Reischl TM. Measuring the climate for health at organizations. Development of the worksite health climate scales. $J$ Occup Med. (1993) 35:812-24. doi: 10.1097/00043764-199308000-00019

40. Schneider B, Ehrhart MG, Macey WH. Organizational climate and culture. Ann Rev Psychol. (2013) 64:36188. doi: 10.1146/annurev-psych-113011-143809

41. Kwon Y, Marzec ML, Edington DW. Development and validity of a scale to measure workplace culture of health. J Occup Environ Med. (2015) 57:5717. doi: 10.1097/JOM.0000000000000409

42. Brehm BJ, Gates DM, Singler M, Succop PA, D'Alessio DA, Brehm BJ, et al. Environmental changes to control obesity: a randomized controlled trial in manufacturing companies. Am J Health Promot. (2011) 25:33440. doi: 10.4278/ajhp.090128-QUAN-37

43. Linde JA, Nygaard KE, MacLehose RF, Mitchell NR, Harnack LJ, Cousins JM, et al. HealthWorks: results of a multi-component grouprandomized worksite environmental intervention trial for weight gain prevention. Int J Behav Nutr Phys Act. (2012) 9:14. doi: 10.1186/1479-58 68-9-14

44. Kushida O, Murayama N. Effects of environmental intervention in workplace cafeterias on vegetable consumption by male workers. J Nutr Educ Behav. (2014) 46:350-8. doi: 10.1016/j.jneb.2014.05.001

45. Kahn-Marshall JL, Gallant MP. Making healthy behaviors the easy choice for employees: a review of the literature on environmental and policy changes in worksite health promotion. Health Educ Behav. (2012) 39:75276. doi: 10.1177/1090198111434153

46. Verweij LM, Coffeng J, van Mechelen W, Proper KI. Metaanalyses of workplace physical activity and dietary behaviour interventions on weight outcomes. Obes Rev. (2011) 12:40629. doi: 10.1111/j.1467-789X.2010.00765.x

47. Flynn JP, Gascon G, Doyle S, Matson Koffman DM, Saringer C, Grossmeier J, et al. Supporting a culture of health in the workplace: a review of evidence-based elements. Am J Health Promot. (2018) 32:175588. doi: 10.1177/0890117118761887

48. Taylor AW, Pilkington R, Montgomerie A, Feist H. The role of business size in assessing the uptake of health promoting workplace initiatives in Australia. BMC public health. (2016) 16:353. doi: 10.1186/s12889-016-3011-3

49. Pescud M, Teal R, Shilton T, Slevin T, Ledger M, Waterworth $\mathrm{P}$, et al. Employers' views on the promotion of workplace health and wellbeing: a qualitative study. BMC Public Health. (2015) 15:642. doi: 10.1186/s12889-015-2029-2

50. Linnan L, Bowling M, Childress J, Lindsay G, Blakey C, Pronk S, et al. Results of the 2004 National Worksite Health Promotion Survey. Am J Public Health. (2008) 98:1503-9. doi: 10.2105/AJPH.2006.100313

51. Schult TM, Galway AM, Awosika ER, Schmunk SK, Hodgson M. Management support, worksite culture, and local resources for healthier employees the veterans affairs experience. J Occup Environ Med. (2013) 55:310-7. doi: 10.1097/JOM.0b013e31827dbale

52. McLellan DL, Cabán-Martinez AJ, Nelson CC, Pronk NP, Katz JN, Allen JD, et al. Organizational characteristics influence implementation of worksite health protection and promotion programs: evidence from smaller businesses. J Occup Environ Med. (2015) 57:1009. doi: 10.1097/JOM.0000000000000517

Conflict of Interest: The authors declare that the research was conducted in the absence of any commercial or financial relationships that could be construed as a potential conflict of interest.

Copyright (C) 2020 Chang, Tsai, Kuo, Yeh and Chen. This is an open-access article distributed under the terms of the Creative Commons Attribution License (CC BY). The use, distribution or reproduction in other forums is permitted, provided the original author(s) and the copyright owner(s) are credited and that the original publication in this journal is cited, in accordance with accepted academic practice. No use, distribution or reproduction is permitted which does not comply with these terms. 